\title{
Rethinking the Concept of Team Teaching for English and Non- English Course
}

\author{
Rizkiana Maharddhika \\ Universitas Brawijaya \\ r-maharddhika@ub.ac.id
}

\begin{abstract}
Generally, a course is taught by one lecturer during one semester. However, one of the institutions in Malang implemented a team teaching model in almost all courses either English or Non-English course. The courses with two and three credits are strongly advised to implement the team teaching model. In this institution, team teaching model is one subject taught by two lecturers; one lecturer for seven meetings before the middle test, and another different lecturer for seven meetings after the middle test. In other words, students will meet two lecturers for one course in one semester in turn. Hence, in this study, the researcher aims to elaborate the concept of team teaching model implemented in this institution. Then, it compared to the real concept of team teaching implementation from other discussions. As a result, there was a bit misconception in the implementation of team teaching concept in this institution. Overall, this study hopefully contributes the insight of team teaching concept for this institution that could be implemented to all courses properly later on.
\end{abstract}

Keywords: Team teaching; English Course; Non-English Course.

\section{INTRODUCTION}

Team teaching is kind of collaborative teaching model. It is a word used to define a teaching and learning cooperative strategy. Coteaching, collegial teaching, cooperative teaching, and supplementary training are just a few of the terms found when reviewing team teaching literature (Keast and Cooper, 2014). It allows two teachers or lecturers teach in the same classroom. They teach, assess, and evaluate the students' achievement.

Team teaching is a model of learning in which the educators work together to prepare, teach and evaluate a course (Simons et.al, 2019). In medical school, team teaching is a common techniques used to deliver content with an integrated curriculum (Lee and Soborowicz, 2015).

The concept of team teaching contributed some advantages in language education. However, the prevalent obstacles can be created by real-world limitations, such as an absence of training time, or by private or cultural variable (Pearce, 2019). In term of students' achievement, Carpenter et.al (2007) found that graduate students in a team teaching studies and statistics course did not show a considerably higher mean performance rating than those in the solo-teaching segment when using the performance test as a measure. In reality, it seemed that the former learners performed worse.

Based on some previous studies above, it was found that the concept of team teaching is having 
two educators taught in the classroom at the same time. The impacts of using team teaching concept were also revealed.

Therefore, this study aims to elaborate the concept of team teaching as defined and implemented by one of institution in Malang, and then compare it to the existing concept of team teaching conducted by other previous studies. Since the researcher is one of the practitioners of team teaching concept in this institution, the information of team teaching concept was gained easily.

Later on, this study hopefully can contribute the insight about the real concept of team teaching. Thus, the institution can make further step to prepare and implement team teaching model in each faculty properly.

\section{THE IMPLEMENTATION OF TEAM-TEACHING CONCEPT}

Before discussing the existing concept of team teaching as conducted by other researchers, the researcher tried to elaborate the definition of team teaching concept in one of institutions in Malang.

Team teaching is defined as having two lecturers in one semester to teach the same course, same classroom but not at the same time. The objective of having two lecturers in one semester was the students hopefully can obtain new and fresh knowledge from two different people even not at the same time.

The procedure was one lecturer taught for seven meetings before middle test and another lecturer taught for seven meetings after middle test. Yet, both lecturers taught alone in the classroom. They did not conduct any collaboration.

Even though two lecturers were assigned to hold the same class in one semester, they still teach, assess and evaluate individually. As an example, an English course taught by lecturer ' $\mathrm{A}$ ' and ' $\mathrm{B}$ '. During seven meetings before middle test (UTS), lecturer ' $A$ ' prepared the material as well as the assessment including middle test by him/her self. Then, the students' middle test score will be submitted to the lecturer ' $\mathrm{B}$ ' to be calculated for final score later on. The job of lecturer ' $A$ ' was ended and it will be continued by his/her partner, lecturer 'B'.

Likewise, lecturer ' $\mathrm{B}$ ' prepared the material for next seven meetings as well as the final examination (UAS) by him/her self. At the end of the semester, lecturer ' $\mathrm{B}$ ' had full responsibility to make a decision of students' final score without asking any consideration from lecturer ' $A$ '.

The explanation above shows the general concept of team teaching in this institution. This kind of concept had been implemented for several periods and still continues until today.

\section{THE EXISTING CONCEPT OF TEAM TEACHING}

\section{Team Teaching Concept Promoted By Other Researchers}

After knowing the concept of team teaching implemented by the institution above, here the researcher tried to compare with the existing concept of team teaching promoted 
by other researchers. First, the researcher elaborated the concept promoted by Baeten and Simons (2014). They promoted five concepts or models of team teaching.

The five concepts were the observation model, the coaching model, the assistant teaching model, the equal status model and the teaming model. The concepts of each model were elaborated as follows:

1. The observation model allows one teacher teaches and another teacher observes. In this occasion, the observer will collect some information on effective teaching behaviour and also the interaction with learners.

2. The coaching model: more accountability is given to the observer. Suggestions, aid and support should be provided by the coach. Teacher can coach each other or mentor each other.

3. The assistant teaching model: one educator is fully responsible for delivering the course. Another educator is an assistant who, when needed, provides assistance to students.

4. The equal status model: both educators are of equal status. In this model, there were three sub-models such as the sequential teaching, parallel teaching, and station teaching.

- Sequential teaching: teacher split the content or activities of teaching. The same group of learners are taught the same lesson. But each teacher is responsible for various lesson/course stages. If one teacher teaches, there is no need for another teacher to be present in the classroom.

- Parallel teaching: educators split the group into subgroups and teach subgroups the same data. They can rotate among the subgroups.

- Station teaching: educators split learning content or activities with each teacher working on a particular learning content or activity with a learner subgroup. Both educators usually plan the training.

5. The teaming model: both educators share responsibilities (planning, delivery and assessment) in a fair manner. Both are in front of the class group as a whole and there is a lot of interaction and dialog between them.

Another researcher promoted the advanced concept of team teaching. Yorita and Kubota (2010) described the role of robots in distant education based on teamteaching. Robot partners can assist a teacher and facilitate classes. Robot edutainment has three distinct goals, for example: learning on robots, learning through robots, and learning with robots. This concept of team teaching used technology to assist educator in teaching the students.

\section{Advantages and Disadvantages}

The concept of team teaching has both advantages and disadvantages. Robb and Gerwick (2013) found that learners can experience in one course a range of learning teachniques. Developing a 
powerful working connection between team members is another advantage. Yet, absence of ownership of courses, inter-reader teamwork, and personal conflict were the disadvantages of team teaching. As a consequence, learners may feel the discrepancy between the instructors' team and criticize the course delivery. This may lead to adverse instructor assessments and course assessments.

Another advantages and disadvantages were revealed by Ulrich and Nedelcu (2013). They concluded that team teaching experience is viewed as beneficial and the faculty supports it. Yet, lack of information may lead to misinterpretation of this kind of mixed activity.

\section{DISCUSSION}

Based on the explanation above, the concept of team teaching implemented in this institution had a bit misinterpretation. The institution had already had two lecturers for one course. It is in line with the existing concept of team teaching generally.

Yet, a bit misconception was lack of the collaboration of preparing, assessing and evaluating the students' progress during teaching and learning process.

Fortunately, the concept of team teaching conducted by this institution was slightly similar with the forth concept of team teaching promoted by Baeten and Simons (2014) that is Sequential teaching. As stated in previous section, sequential teaching means that when one teacher teaches, there is no need for another teacher to be present in the classroom.

\section{CONCLUSION}

Based on the explanation above, the concept of team teaching in this institution is slightly similar to the concept of Sequential Teaching. Yet, the institution is suggested to conduct deep preparation in implementing the proper concept of team teaching in the future. It should cover collaboration either in teaching, assessing, or evaluating because a team teaching is about collaboration.

Finally, there is no further investigation on the barriers faced by two lecturers during team teaching. It is suggested for the next researchers to conduct a research focusing on the barriers faced by two lecturers doing collaboration in teaching process. The students' perspective on team teaching is also worth investigating.

\section{REFERENCE}

Baeten, Marlies., Simons, Mathea. (2014). Student teachers' team teaching: Models, effects, and conditions for implementation. Teaching and Teacher Education 41 (2014) 92 - 110

Carpenter, D.M., Crawford, L. \& Walden, R. Learning Environ. Res (2007)10:53. https://doi.org/10.1007/s10984 -007-9019-y

Keast S., Cooper R. (2014) Team Teaching. In: Gunstone R. (eds) Encyclopedia of Science 
Education. Springer, Dordrecht

Lee, M.W. \& Soborowicz, M.B. Med.Sci.Educ. (2015) 25: 497. https://doi.org/10.1007/s40670$\underline{015-0167-\mathrm{x}}$

Pearce, Daniel Roy (2019) A Systems Approach to Language Pedagogy pp 99119, Part of the Translational Systems Sciences book series (TSS, volume 17)

Robb, Meigan MS, RN., Gerwick, Michele PhD,RN., Team teaching: a resource guide for nurse educators. Teaching and Learning in Nursing (2013) 8, 7882

Simons, M., Coetzee, S., Baeten, M. et al. Learning Environ Res (2019).https://doi.org/10.1007/ s10984-019-09290-1

Ulrich, Catalina., Nedelcu, Anca., Team Teaching and Team work: perceptions amongst students and staff (a case study). Procedia - Social and Behavioral Sciences 76 (2013) $853-857$

Yorita A., Kubota N. (2010) Essential Technology for Team Teaching Using Robot Partners. In: Liu H., Ding H., Xiong Z., Zhu X. (eds) Intelligent Robotics and Applications. ICIRA 2010. Lecture Notes in Computer Science, vol 6425. Springer, Berlin, Heidelberg 